\title{
X-linked Charcot-Marie-Tooth disease type 3
}

INSERM

\section{Source}

INSERM. (1999). Orphanet: an online rare disease and orphan drug data base. X-linked Charcot-Marie-Tooth disease type 3. ORPHA:101077

X-linked Charcot-Marie-T ooth disease type 3 is a rare, genetic, peripheral sensorimotor neuropathy characterized by an X-linked recessive inheritance pattern and the childhoodto adolescent-onset of progressive, distal muscle weakness and atrophy (beginning in the lower extremities and then affecting the upper extremities), as well as distal, pansensory loss in the upper and lower extremities, pes cavus, and absent or reduced distal tendon reflexes. Pain and paresthesia are frequently the initial sensory symptoms. Spastic paraparesis (manifested by clasp-knife sign, hyperactive deep-tendon reflexes, and Babinski sign) has also been reported. 